Check for updates

Cite this: RSC Adv., 2019, 9, 4892

Received 29th December 2018 Accepted 22nd January 2019

DOI: 10.1039/c8ra10629k

rsc.li/rsc-advances

\title{
A novel method for the highly efficient biotransformation of genistein from genistin using a high-speed counter-current chromatography bioreactor
}

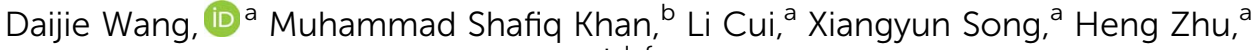 \\ Tianyu Ma, ${ }^{\text {ac }}$ Xiaoyu $\mathrm{Li}^{\mathrm{C}}$ and Rong Sun ${ }^{\star d e f}$
}

Genistein, an important soybean isoflavone compound, has gained attention for its significant properties. Compared with the glycone form of genistin, low content of genistein limits the use in food and pharmaceutical fields. In this study, a novel bioreactor with high-speed counter-current chromatography (HSCCC) was built for the highly efficient biotransformation of genistein from genistin. The solvent system for the bioreactor was selected according to the $K_{D}$ values. The selected solvent system was evaluated by the enzyme activity of $\beta$-glucosidase. An ethyl acetate/buffer solution was selected as the preferred solvent system for the HSCCC bioreactor. Optimum reactor parameters were selected according to the retention of the stationary phase. The HSCCC bioreactor was operated using different flow rates, and $2.0 \mathrm{~mL} \mathrm{~min} \mathrm{~m}^{-1}$ was chosen as the optimal flow rate with a conversion rate of over $90 \%$ within $24 \mathrm{~h}$; the novel bioreactor easily immobilized and recycled the enzyme and could be applied in the preparation of genistein.
\end{abstract}

\section{Introduction}

Genistein (4' $4^{\prime}, 5,7$-trihydroxyisoflavone), an important isoflavone compound, is widely distributed in leguminous plants such as soybeans, Pueraria lobata (Willd.) Ohwi and Sophora japonica L. Genistein is structurally similar to estrogen and has a number of biological properties that can prove beneficial in alleviating a variety of health conditions including kidney disease, menopausal symptoms, neuronal loss, Alzheimer's disease, and cancer. ${ }^{1-7}$ Because of this broad range of biological properties, genistein has gained attention as a food additive and dietary supplement. Currently, there is an enormous demand for genistein in health and food products.

Genistein is a glycone form of genistin ( $4^{\prime}, 5,7$-trihydroxyisoflavone- $\beta$-D-glucopyranoside) with a higher potential for intestinal absorption than genistin., ${ }^{\mathbf{8} 9}$ Genistein has also shown

\footnotetext{
${ }^{a}$ Key Laboratory of TCM Quality Control, Shandong Analysis and Test Center, Qilu University of Technology (Shandong Academy of Sciences), Jinan 250014, P. R. China ${ }^{b}$ Department of Biotechnology and Bioinfomatics, International Islamic University, Islamabad 44000, Islamic Republic of Pakistan

${ }^{c}$ College of Pharmacy, Shandong University of Traditional Chinese Medicine, Jinan, China

${ }^{d}$ Institute of Advanced Medical Science, Shandong University, Jinan 250012, P. R. China.E-mail: sunrong@sdu.edu.cn

${ }^{e}$ The Second Hospital of Shandong University, Jinan 250033, P. R. China

${ }^{f}$ The Post of Taishan Scholar in Traditional Chinese Medicine Pharmacology and Toxicology, Jinan 250033, P. R. China
}

stronger antioxidant potency in DPPH radical-scavenging and LDL oxidation assays than genistin. ${ }^{\mathbf{1 0}}$ However, genistein is mainly present as a glycoside form of genistin in soybeans. Therefore, the conversion of genistein from genistin is very important. There are many methods for the transformation of genistin to genistein, which include alkaline/acidic hydrolysis and microbial and enzymatic transformations, as shown in Fig. 1. ${ }^{11-13}$ Alkaline or acidic hydrolysis always results in a strong reaction and causes environmental pollution. On the other hand, biotransformation using enzymes or microorganisms has many advantages including simplicity of procedure, mild conditions, low cost, and less pollution of the environment. To provide efficient biotransformation conditions, many types of reactors need to be built. These include a membrane, a packed bed, and an immobilized enzyme reactor. ${ }^{\mathbf{1 4}, 15}$ There are also many obstacles that need to be overcome such as physical damage to the membrane, membrane pollution, cleaning of the immobilized enzyme, and enzyme recycling.

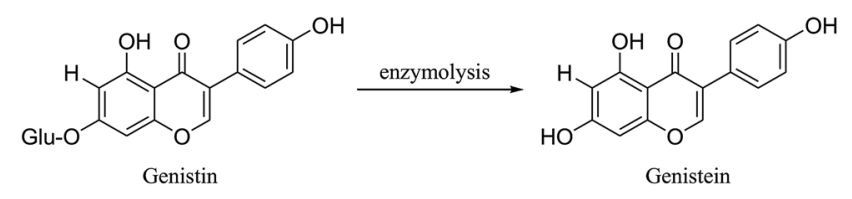

Fig. 1 Chemical structures of the compounds and a schematic of enzymolysis. 
High-speed counter-current chromatography (HSCCC) is a liquid-liquid partition chromatographic technique that eliminates the possibility of irreversible sample adsorption on a solid support. Furthermore, HSCCC provides high recovery and rapid and effective separation, is easily scaled-up and simple to operate, and has low solvent consumption. It has recently become a useful tool for the preparative isolation and purification of various natural products. ${ }^{16-19}$ The HSCCC column is a hollow polytetrafluoroethylene coil twining around the HSCCC column holder. The two-phase solvent system is set at a high distribution rate of over 13 times per second (a rotation speed of $800 \mathrm{rpm}$ ) (Fig. 2). When the enzyme or microorganism remains in the stationary phase of the HSCCC solvent system and the substrate continues to be eluted in the mobile phase, a novel biotransformation reactor is constructed. There are many advantages of this novel reactor such as a decrease in substrate inhibition, contact between the enzyme and the substrate, and high purity of products outflowing in the mobile phase.

In this study, a novel HSCCC bioreactor was built for the highly efficient biotransformation of genistin to genistein. The bioreactor parameters, the type of enzyme used, and the flow rate of the mobile phase were optimized. To the best of our knowledge, to date, an HSCCC bioreactor has not been used for the biotransformation of genistein. In this study, an attempt was made to perform a biotransformation of genistin to genistein using HSCCC. This method could be used to transform other compounds and enriches the types of bioreactors.

\section{Materials and methods}

\subsection{Reagents and materials}

$n$-Hexane, methanol, citric acid, sodium citrate, ethyl acetate, $n$ butanol, acetic acid and dichloromethane were analytical grade (Sinopharm Chemical Reagent Co., Ltd, Shanghai, China). $p$ Nitrophenyl $\beta$-D-glucopyranoside $(p$-NPG) and $\beta$-glucosidase were biochemical grade (Sangon Biotech Co., Ltd. Shanghai,
China). HPLC-grade methanol was purchased from the Fisher Company (Fairlawn, NJ, USA). Water used was deionized by an osmosis Milli-Q system (Millipore, Bedford, MA, USA). Reverse osmosis Milli-Q water (Millipore, USA) was used in this study. The purities of genistin and genistein were over 98\% (HPLC, Desite Biotech Co., Ltd. Chengdu, China).

\subsection{Apparatus}

The HSCCC equipment was TBE-300A (Shanghai, Tauto Biotech, China) with three $300 \mathrm{~mL}$ multi-layer coil separation columns (diameter of the PTFE tube was $1.6 \mathrm{~mm}$ ) as well as a $20 \mathrm{~mL}$ manual sample loop. The $\beta$-values of the HSCCC column ranged from 0.47 (internal) to 0.73 (external) $(\beta=r / R$, where $r$ is the rotation radius or the distance from the coil to the holder shaft, and $R(R=7.5 \mathrm{~cm})$ is the revolution radius or the distance between the holder axis and the central axis of the centrifuge). The HSCCC apparatus was equipped with four other instrument modules, i.e. a 8823A-UV monitor at $280 \mathrm{~nm}$ (Beijing Emilion Technology, Beijing, China), a Model 3057 portable recorder (Yokogawa, Sichuan Instrument Factory, Sichuan, China), a TBP-5002 constant-flow pump and a DC-0506 low constant temperature bath (Tauto Biotechnique, Shanghai, China), to maintain the temperature at $40{ }^{\circ} \mathrm{C}$. The spectrophotometer used was the Genesys 10S UV-Vis scanning spectrophotometer (Thermo Fisher Scientific, Waltham, MA, USA). HPLC separation was performed using the Agilent 1260 system (Agilent Technologies, USA) consisting of a quaternary solvent delivery system, vacuum degasser, diode array detector (DAD), auto-sampler and column oven connected to the Agilent ChemStation software. The HPLC column used was the Waters Symmetry $\mathrm{C}_{18}$ column $(250 \mathrm{~mm} \times 4.6 \mathrm{~mm}$, i.d. $5 \mu \mathrm{m}$, USA $)$.

\subsection{Determination of the partition coefficient}

The partition coefficient $\left(K_{\mathrm{D}}\right)$ of the substrate and the product in different solvent systems was determined by HPLC. The substrate (genistin) and the product (genistein) at appropriate
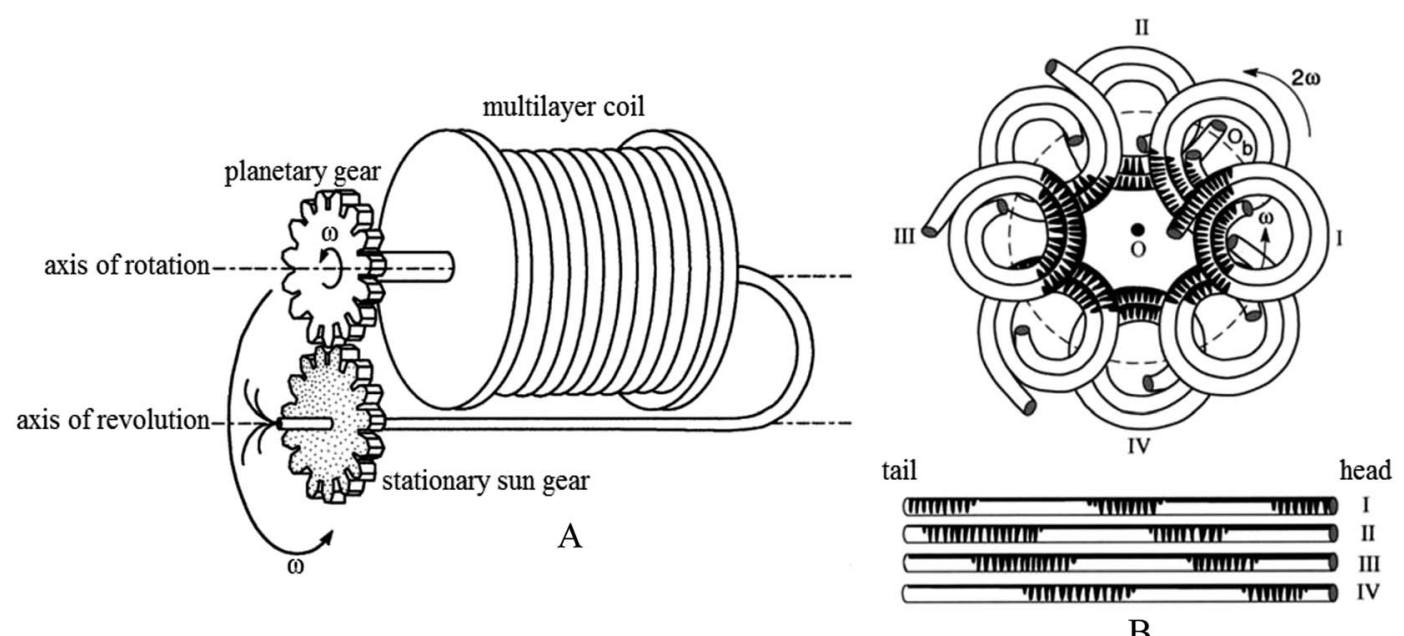

Fig. 2 The instrument construction of the HSCCC reactor. (A) Type-J planetary motion of the HSCCC multi-layer coil column. (B) Schematic of the distribution and motion of two phases in the HSCCC column. 
amounts were placed in $5 \mathrm{~mL}$ test tubes, dissolved with the stationary phase of the two-phase solvent system, and detected by HPLC. The peak areas $A_{\mathrm{S} 1}$ and $A_{\mathrm{P} 1}$ were obtained. An equal volume of the mobile phase solution was added to the lower phase solution followed by vigorous shaking to ensure complete mixing. After the equilibrium of the partition was reached, the stationary phase was analyzed by HPLC to obtain the peak areas $A_{\mathrm{S} 2}$ and $A_{\mathrm{P} 2}$. The $K_{\mathrm{D}}$ value was defined as the peak area of the target compound in the stationary phase divided by the peak area of the target compound in the mobile phase. The partition coefficients of the substrate and product were calculated as follows: $K_{\mathrm{SD}}=\left(A_{\mathrm{S} 1}-A_{\mathrm{S} 2}\right) / A_{\mathrm{S} 2}, K_{\mathrm{PD}}=\left(A_{\mathrm{P} 1}-A_{\mathrm{P} 2}\right) / A_{\mathrm{P} 2}$.

The partition coefficient of $\beta$-glucosidase was determined in a two-phase solvent system and analyzed as follows: $2 \mathrm{mg}$ of $\beta$ glucosidase was fully dissolved in $6 \mathrm{~mL}$ of the stationary phase solution of the two-phase solvent system to obtain solution A. Then, $3 \mathrm{mg}$ of $p$-NPG was fully dissolved in $1 \mathrm{~mL}$ of the stationary phase solution to obtain solution B. Furthermore, $2 \mathrm{~mL}$ of solution A and $1 \mathrm{~mL}$ of solution $\mathrm{B}$ were heated in a $45^{\circ} \mathrm{C}$ water bath for $30 \mathrm{~min}$, and $1 \mathrm{~mL}$ of $1 \mathrm{~mol} \mathrm{~L}^{-1} \mathrm{Na}_{2} \mathrm{CO}_{3}$ solution was added to terminate the reaction. The absorbance $E_{1}$ was measured by a spectrophotometer at $400 \mathrm{~nm}$. Then, $4 \mathrm{~mL}$ of solution A was mixed with an equal volume of the mobile phase solution of the two-phase solvent system followed by vigorous shaking to ensure complete mixing. After the equilibrium of the partition was reached, $2 \mathrm{~mL}$ of the lower phase solution was heated with $1 \mathrm{~mL}$ of solution $\mathrm{B}$ in a $45{ }^{\circ} \mathrm{C}$ water bath for $30 \mathrm{~min}$. The reaction was terminated by adding $1 \mathrm{~mL}$ of $1 \mathrm{~mol} \mathrm{~L}^{-1}$ $\mathrm{Na}_{2} \mathrm{CO}_{3}$ solution, and the absorbance $E_{2}$ was measured by a spectrophotometer at $400 \mathrm{~nm}$. The reference solution was prepared by heating an inactivated $\beta$-glucosidase solution A ( $2 \mathrm{mg}$ of inactivated $\beta$-glucosidase in $6 \mathrm{~mL}$ of the stationary phase solution) with $1 \mathrm{~mL}$ of solution $\mathrm{B}$ in a $45^{\circ} \mathrm{C}$ water bath for $30 \mathrm{~min}$. The reaction was terminated by adding $1 \mathrm{~mL}$ of $1 \mathrm{~mol} \mathrm{~L}^{-1} \mathrm{Na}_{2} \mathrm{CO}_{3}$ solution, and the absorbance $E_{0}$ was measured by a spectrophotometer at $400 \mathrm{~nm}$. The partition coefficient of $\beta$-glucosidase in the two phases was calculated using the following formula: $K_{\mathrm{D}}=\left(E_{1}-E_{2}\right) /\left(E_{2}-E_{0}\right)$.

\subsection{Determination of the maximum solubility and enzyme activity}

After $2.0 \mathrm{mg}$ of $\beta$-glucosidase was accurately weighed, the stationary phase of the two-phase solvent system was gradually added under sonication. When the solution became clear, its volume was determined, and the maximum solubility of $\beta$ glucosidase was determined to be $750 \mathrm{mg} \mathrm{L}^{-1}$. Then, $2.0 \mathrm{mg}$ of genistin was accurately weighed, and the mobile phase of the two-phase solvent system was gradually added under sonication. When a clear solution was obtained, its volume was determined, and the maximum solubility of genistin was determined to be $62.5 \mathrm{mg} \mathrm{L}^{-1}$.

Aqueous solutions of citric acid and sodium citrate at $0.10 \mathrm{~mol} \mathrm{~L}^{-1}$ were separately prepared, mixed, and filtered, and a citric acid/sodium citrate blank buffer solution $(\mathrm{pH}=5)$ was obtained. Then, $600 \mathrm{~mL}$ of a two-phase solvent system consisting of equal volumes of ethyl acetate and buffer solution was placed in a separatory funnel, to which $120 \mathrm{mg}$ of enzyme was added. The funnel was placed on a shaker for uninterrupted mixing. Every $4 \mathrm{~h}, 6 \mathrm{~mL}$ of the upper and lower phase solutions were sampled. The organic phase was discarded, and the aqueous phase was divided into three equal portions. Each portion was mixed with $2 \mathrm{~mL}$ of $0.8 \mathrm{mg} \mathrm{mL}^{-1} p$-NPG solution and heated in a $45^{\circ} \mathrm{C}$ water bath for $30 \mathrm{~min}$. Next, $2 \mathrm{~mL}$ of $1.0 \mathrm{~mol} \mathrm{~L}^{-1} \mathrm{Na}_{2} \mathrm{CO}_{3}$ aqueous solution was added to terminate the reaction, and changes in the color of the solution were observed. The absorbance values $A_{\mathrm{Y} 1}, A_{\mathrm{Y} 2}$, and $A_{\mathrm{Y} 3}$ were measured at $400 \mathrm{~nm}$, and the average absorbance value $\bar{A}_{\mathrm{Y}}$ was calculated.

The blank and reference solution were prepared by mixing $2 \mathrm{~mL}$ of $0.4 \mathrm{mg} \mathrm{mL}^{-1}$ initial and inactivated $\beta$-glucosidase buffer solution with $2 \mathrm{~mL}$ of $0.8 \mathrm{mg} \mathrm{mL}^{-1} p$-NPG solution, which were then heated in a water bath at $45{ }^{\circ} \mathrm{C}$ for $30 \mathrm{~min}$. The reactions were terminated by the addition of $2 \mathrm{~mL}$ of $1 \mathrm{~mol} \mathrm{~L}^{-1} \mathrm{Na}_{2} \mathrm{CO}_{3}$ solution. Moreover, the absorbances $A_{\mathrm{M}}$ (blank) and $A_{0}$ (reference) at $400 \mathrm{~nm}$ were measured by a spectrophotometer. Each measurement was averaged three times, and the average enzyme activity was calculated using the following formula: enzyme activity $/ \%=\left(\bar{A}_{\mathrm{Y}}-A_{0}\right) \times 100 \% /\left(A_{\mathrm{M}}-A_{0}\right)$.

\subsection{Optimization of the HSCCC reactor parameters}

During the process of counter-current chromatography, there were two modes of rotation direction for the main unit: forward rotation (FWD) and reverse rotation (REV). The input port could serve as the inlet (IN) or the outlet (OUT) of the main unit. Therefore, there were four elution modes for the counter-current chromatography: REV-IN, FWD-OUT, FWD-IN, and REV-OUT. In this experiment, we tested the retention of the stationary phase using an ethyl acetate/ buffer solution $(1: 1, \mathrm{v} / \mathrm{v})$ solvent system, four elution modes of the counter-current chromatography (REV-IN, FWD-OUT, FWD-IN, and REV-OUT), the lower phase as the stationary phase, and the upper phase as the mobile phase. At first, the entire length of the Teflon tubing of the high-speed counter-current chromatography system was filled with the stationary phase solution at the flow rate of $30 \mathrm{~mL} \mathrm{~min}{ }^{-1}$; once the main unit was initiated, the rotation speed was slowly adjusted to $800 \mathrm{rpm}$, and the temperature was maintained at $40{ }^{\circ} \mathrm{C}$. After the rotation speed stabilized, the mobile phase was pumped in at $2 \mathrm{~mL} \min ^{-1}$ until equilibrium was reached. After the rotation was stopped, the two-phase solvent system in the separation column was transferred under nitrogen to a graduated cylinder to calculate the retention of the stationary phase $\left(S_{\mathrm{f}}\right)$ such that $S_{\mathrm{f}}(\%)=\left(V_{\mathrm{S}} / V_{\mathrm{T}}\right) \times 100 \%$, where $V_{\mathrm{S}}$ is the volume of the stationary phase and $V_{\mathrm{T}}$ is the total volume of the HSCCC column.

In this experiment, $S_{\mathrm{f}}$ was measured in parallel at 550, 600, $650,700,750$, and $800 \mathrm{rpm}$. The measurement method was the same as that used for different elution modes, and each measurement was averaged three times.

\subsection{Operation of the HSCCC bioreactor}

2.6.1 Preparation of the two-phase solvent and sample solutions. The ethyl acetate/buffer solution $(1: 1, \mathrm{v} / \mathrm{v})$ solvent system was placed in a separatory funnel, fully shaken, and allowed to stand for phase separation. After the two phases 
reached equilibrium, the upper and lower phases were separately sampled and degassed by ultrasonication. According to the requirements of the counter-current chromatography bioreactor, the following three solutions were prepared: (1) a portion of the upper phase solution was used as the mobile phase of the counter-current chromatography system, to which genistin was added and allowed to fully dissolve under ultrasonication to obtain a substrate solution of $62.5 \mathrm{mg} \mathrm{L}^{-1}$; (2) the lower phase was the stationary phase, to which $\beta$-glucosidase was added and fully mixed to prepare a $750 \mathrm{mg} \mathrm{L}^{-1}$ bioreactor enzyme solution; and (3) a portion of the upper phase solution was stored as the blank mobile phase. The abovementioned three solutions were kept in a $40{ }^{\circ} \mathrm{C}$ water bath before use.

2.6.2 Operation of the HSCCC bioreactor. At first, an enzyme solution of the bioreactor was pumped into the entire HSCCC column at the flow rate of $30 \mathrm{~mL} \mathrm{~min}{ }^{-1}$. After the loading was completed, the main unit was started. Using the FWD-OUT mode (rotating in a clockwise direction), the mobile phase was pumped in from the end of the HSCCC column. The rotation speed was adjusted to $800 \mathrm{rpm}$, and the blank mobile phase was introduced at the end of the counter-current chromatography separation column at a certain flow rate. After the two-phase solvent system reached hydrodynamic equilibrium, the substrate mobile phase solution containing genistin was pumped in. The detector was turned on, the detector wavelength was set at $254 \mathrm{~nm}$, and the recorder was started to initiate data acquisition. The eluted solution was obtained in $10 \mathrm{~mL}$ test tubes.

After biotransformation of genistin by the HSCCC bioreactor, $1 \mathrm{~mL}$ of the eluted solution was periodically obtained, dried with nitrogen, re-dissolved with methanol, and filtered with a $0.45 \mu \mathrm{m}$ needle filter. The conversion rate of the target peak was analyzed by HPLC. After the conversion dropped below a certain value, the run was stopped, the liquid in the separation column was extracted with nitrogen, and $S_{\mathrm{f}}$ was calculated.

\subsection{HPLC analysis condition and structural identification}

The mobile phase comprised methanol/water $(70: 30, \mathrm{v} / \mathrm{v})$, with

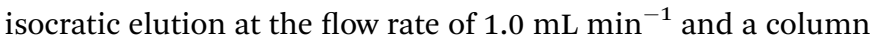
temperature of $30{ }^{\circ} \mathrm{C}$. The detection wavelength was set at $254 \mathrm{~nm}$, and the injection volume was $10 \mu \mathrm{L}$.

The identification of the converted product was performed via mass spectrometry (ESI-MS) with electrospray ionization (ESI)/quadrupole (Q) ESI-MS data (quadrupole LC/MS 6120, Agilent Technologies, Palo Alto, CA) in the direct injection mode, and the MS conditions were as follows: mass range: 100$1000 \mathrm{~m} / \mathrm{z}$, capillary temperature: $300{ }^{\circ} \mathrm{C}$, spray voltage: $4 \mathrm{kV}$, skimmer voltage: $40 \mathrm{~V}$, auxiliary gas (nitrogen) flow: $6 \mathrm{~L} \mathrm{~min}^{-1}$, and positive mode. NMR spectra were obtained using the Bruker AV-400 spectrometer (Bruker BioSpin, Rheinstetten, Germany) with TMS as the internal standard.

\section{Results and discussion}

\subsection{Selection of the solvent system}

The selection of an appropriate two-phase solvent system is one of the key steps in the application of HSCCC as a bioreactor for processing the active ingredients in natural medicines. A suitable two-phase solvent system requires that (1) the enzymes are mainly distributed in the stationary phase since distribution in the mobile phase results in a loss of enzymes; (2) the product is mainly distributed in the mobile phase and can be rapidly eluted with the mobile phase; and (3) the substrate has good solubility in the mobile phase. Based on the principles of enzymatic reactions, the larger contact area between the substrate and the enzyme could enhance the catalytic efficiency. However, HSCCC is a partition chromatography in which the substrate undergoes vigorous mixing and partitioning inside the column. Therefore, if the substrate is adequately distributed in the stationary phase of the selected two-phase solvent system, the HSCCC bioreactors can be implemented.

As shown in Table 1, the distribution of the substrate and product was analyzed in the $n$-hexane/buffer solution $(1: 1, \mathrm{v} / \mathrm{v})$, ethyl acetate/buffer solution $(1: 1, \mathrm{v} / \mathrm{v})$, dichloromethane/buffer solution $(1: 1, \mathrm{v} / \mathrm{v})$, and $n$-butanol/buffer $(1: 1, \mathrm{v} / \mathrm{v})$ solution. The results showed that the $K_{\mathrm{D}}$ values in the $n$-hexane/buffer solution solvent system were below 0.1, indicating that both the substrate and product were mainly distributed in the stationary phase, and the product could not be continuously eluted with the mobile phase after enzymatic hydrolysis. Therefore, the $n$-hexane/buffer solution was not suitable as a solvent system for the HSCCC reactors. The remaining solvent systems provided satisfactory $K_{\mathrm{D}}$ values for the substrate and product and could be further tested for enzymatic activity as suitable two-phase solvent systems.

\subsection{Effects of the solvent system on the enzyme activity}

Fig. 3 shows activity changes for $\beta$-glucosidase in three solvent systems: ethyl acetate/buffer $(1: 1, \mathrm{v} / \mathrm{v})$, dichloromethane/buffer $(1: 1, \mathrm{v} / \mathrm{v})$, and $n$-butanol/buffer $(1: 1, \mathrm{v} / \mathrm{v})$ solutions. The results showed that enzyme activity in the dichloromethane/buffer solution solvent system decreased to less than $1 \%$ at $4 \mathrm{~h}$ and to $0 \%$ at $8 \mathrm{~h}$. We suspect that dichloromethane readily denatures $\beta$-glucosidase and thus destabilizes the enzyme structure. Therefore, dichloromethane is not suitable as a solvent for the HSCCC bioreactor. The ethyl acetate/buffer and $n$-butanol/ buffer solution solvent systems provided higher stability of the enzyme activity during the test. The enzyme activity was above $99 \%$ at $48 \mathrm{~h}$, indicating that the ethyl acetate and $n$ -

Table 1 The $K_{D}$-values for resveratrol in a HSCCC bioreactor with different solvent systems ${ }^{a}$

\begin{tabular}{lll}
\hline & $K_{\mathrm{D}}$-values & \\
\cline { 2 - 3 } Solvent systems & Genistin & Genistein \\
\hline$n$-Hexane/buffer solution $(1: 1, \mathrm{v} / \mathrm{v})^{b}$ & $<0.1$ & $<0.1$ \\
Ethyl acetate/buffer solution $(1: 1, \mathrm{v} / \mathrm{v})^{b}$ & 0.66 & $>10$ \\
$n$-Butanol/buffer solution $(1: 1, \mathrm{v} / \mathrm{v})^{b}$ & 3.05 & $>10$ \\
Dichloromethane/buffer solution $(1: 1, \mathrm{v} / \mathrm{v})^{c}$ & $>10$ & $<0.1$
\end{tabular}

${ }^{a}$ The buffer solution contained citric acid $(0.10 \mathrm{M})$ and a sodium citrate buffer solution (pH 5). ${ }^{b}$ Lower phase as the stationary phase. ${ }^{c}$ Upper phase as the stationary phase. 


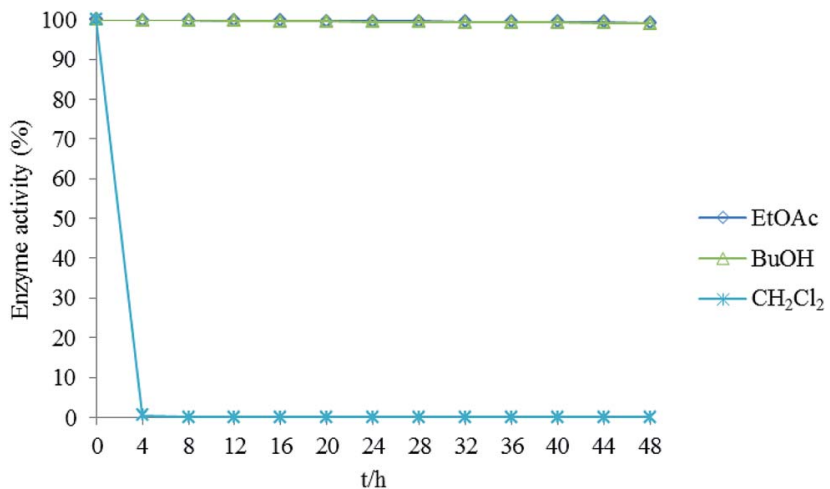

Fig. 3 Effect of the solvent system on enzyme activity. EtOAc: ethyl acetate/buffer solution ( $1: 1, \mathrm{v} / \mathrm{v})$, BuOH: $n$-butanol/buffer solution $(1: 1, v / v)$, and $\mathrm{CH}_{2} \mathrm{Cl}_{2}$ : dichloromethane/buffer solution $(1: 1, \mathrm{v} / \mathrm{v})$.

butanol systems did not readily cause enzyme denaturation. In the $n$-butanol/buffer solution solvent system, the $n$-butanol phase was saturated with a large amount of water. This caused $\beta$-glucosidase to elute with the mobile phase and lowered the enzyme concentration during the operation of the bioreactor. Eventually, the ethyl acetate/buffer solution was selected as the preferred two-phase solvent system for the HSCCC bioreactor.

\subsection{Optimization of the HSCCC reactor parameters}

Fig. 4A shows the $S_{\mathrm{f}}$ of the ethyl acetate/buffer solution solvent system in four HSCCC elution modes (FWD-OUT, REV-IN, FWDIN, and REV-OUT). The results showed that the $S_{\mathrm{f}}$ was higher in the FWD-OUT (64.5\%) and REV-IN (64.6\%) modes, which were
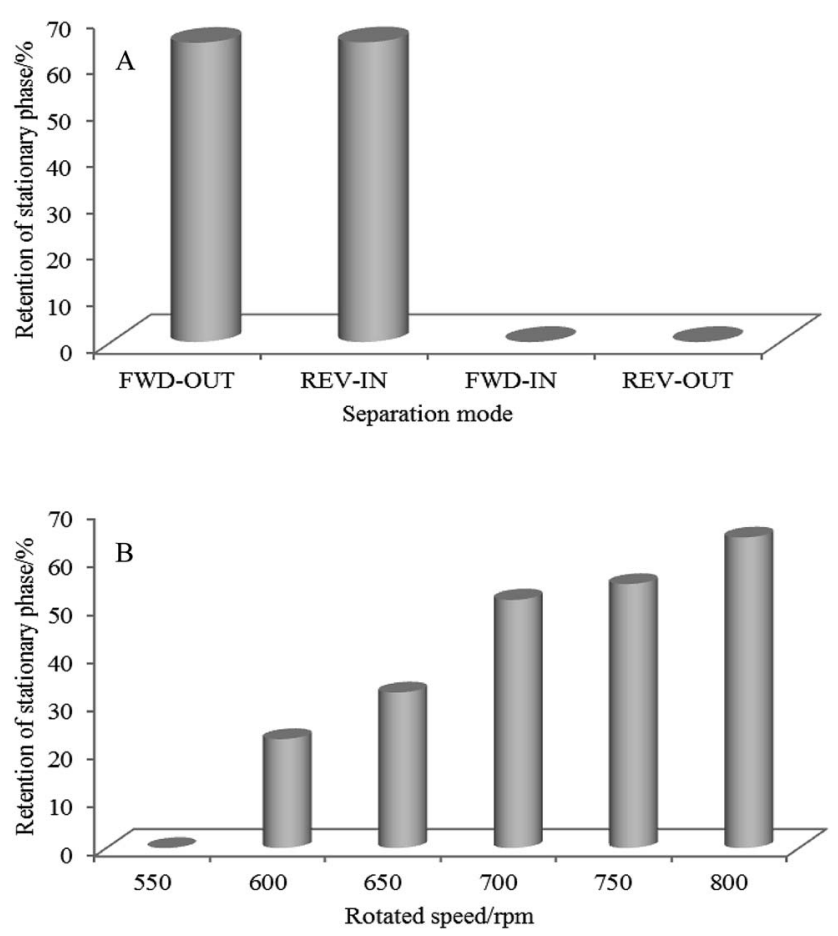

Fig. 4 The results of the optimized HSCCC bioreactor parameters. (A) different separation modes. (B) Different rotated speed. Solvent system: ethyl acetate/buffer solution $(1: 1, \mathrm{v} / \mathrm{v})$. Rotation speed:

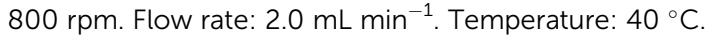

suitable elution modes for the HSCCC reactors. The FWD-IN and REV-OUT modes, under which the $S_{\mathrm{f}}$ was zero, were not suitable for the HSCCC reactors.

Fig. 4B shows the effect of different rotation speeds (i.e. 550, $600,650,700,750$, and $800 \mathrm{rpm}$ ) on the $S_{\mathrm{f}}$ in the FWD-OUT mode. As shown, the $S_{\mathrm{f}}$ was 0 when the rotation speed was $550 \mathrm{rpm}$, and it significantly increased with the increasing rotation speed. The stationary phase retention rate increased to as high as $64.5 \%$ as the rotation speed reached $800 \mathrm{rpm}$. Therefore, the FWD-OUT mode and $800 \mathrm{rpm}$ rotation speed were chosen as the optimal parameters for the HSCCC bioreactor.

\subsection{Optimization of the flow rate for the HSCCC bioreactor}

Fig. 5 shows the HSCCC chromatograms and purity results for the biotransformation of genistin to genistein in the novel bioreactor at the flow rates of 4.0,3.0, 2.0, and $1.0 \mathrm{~mL} \mathrm{~min}^{-1}$. When the flow rate was $3.0 \mathrm{~mL} \mathrm{~min}^{-1}$ (Fig. $5 \mathrm{~A}$ ), the $S_{\mathrm{f}}$ was $42 \%$, and the conversion rate significantly declined within $3 \mathrm{~h}$. It remained stable at $60-65 \%$ during the $3-12 \mathrm{~h}$ time period. When the flow rate continued to decrease to $2.5 \mathrm{~mL} \mathrm{~min}{ }^{-1}$ (Fig. 5B), the retention of the stationary phase was $51 \%$, the absorption curve showed significant fluctuations, and the conversion rate of genistin was initially higher and then decreased over time. The conversion rate of genistin began to rapidly drop after $8 \mathrm{~h}$ and was eventually reduced to $70 \%$ at $14 \mathrm{~h}$. When the flow rate was $2.0 \mathrm{~mL} \mathrm{~min}^{-1}$ (Fig. 5C), the $S_{\mathrm{f}}$ was $62 \%$, and the conversion rate of genistin was initially higher and then decreased over time. The conversion rate was over $90 \%$ within $24 \mathrm{~h}$. When the flow rate was $1.0 \mathrm{~mL} \mathrm{~min}^{-1}$ (Fig. 5D), the $S_{\mathrm{f}}$ was $75 \%$. The absorption value increased in the time period of 1.6$2.4 \mathrm{~h}$, and the conversion rate for genistin reached $100 \%$, followed by a slow decline. This may be attributed to the fact that during the initial introduction of the substrate, the reaction time for the substrate is longer, allowing the substrate to be fully converted in the HSCCC reactor. Within $24 \mathrm{~h}$ of the reaction time, genistin was efficiently processed by $\beta$-glucosidase with over a $99 \%$ conversion rate (Fig. 6).

Based on the abovementioned results, the $S_{\mathrm{f}}$ of HSCCC decreased as the flow rate increased. On the one hand, the increase in the flow rate correlated with the increase in the amount of the substrate entering the reactor. If the substrate was completely converted, the product yield produced per unit of time increased. On the other hand, a decrease in $S_{\mathrm{f}}$ decreased $\beta$-glucosidase, resulting in a decreased amount of the enzyme and an incomplete conversion of the substrate. Consequently, in the operation of the HSCCC bioreactor, a certain balance between the flow rate and $S_{\mathrm{f}}$ was required to achieve a sufficiently high product concentration at the outlet. Based on this study, a flow rate of $2.0 \mathrm{~mL} \mathrm{~min}{ }^{-1}$ was chosen as the optimal flow rate, which provided a conversion rate of over $90 \%$ within $24 \mathrm{~h}$ of the reaction. Moreover, the purity of the product appeared to gradually decrease as the reaction time was extended. A possible explanation for this effect is that after genistin is hydrolyzed, the detached glucose remains in the 

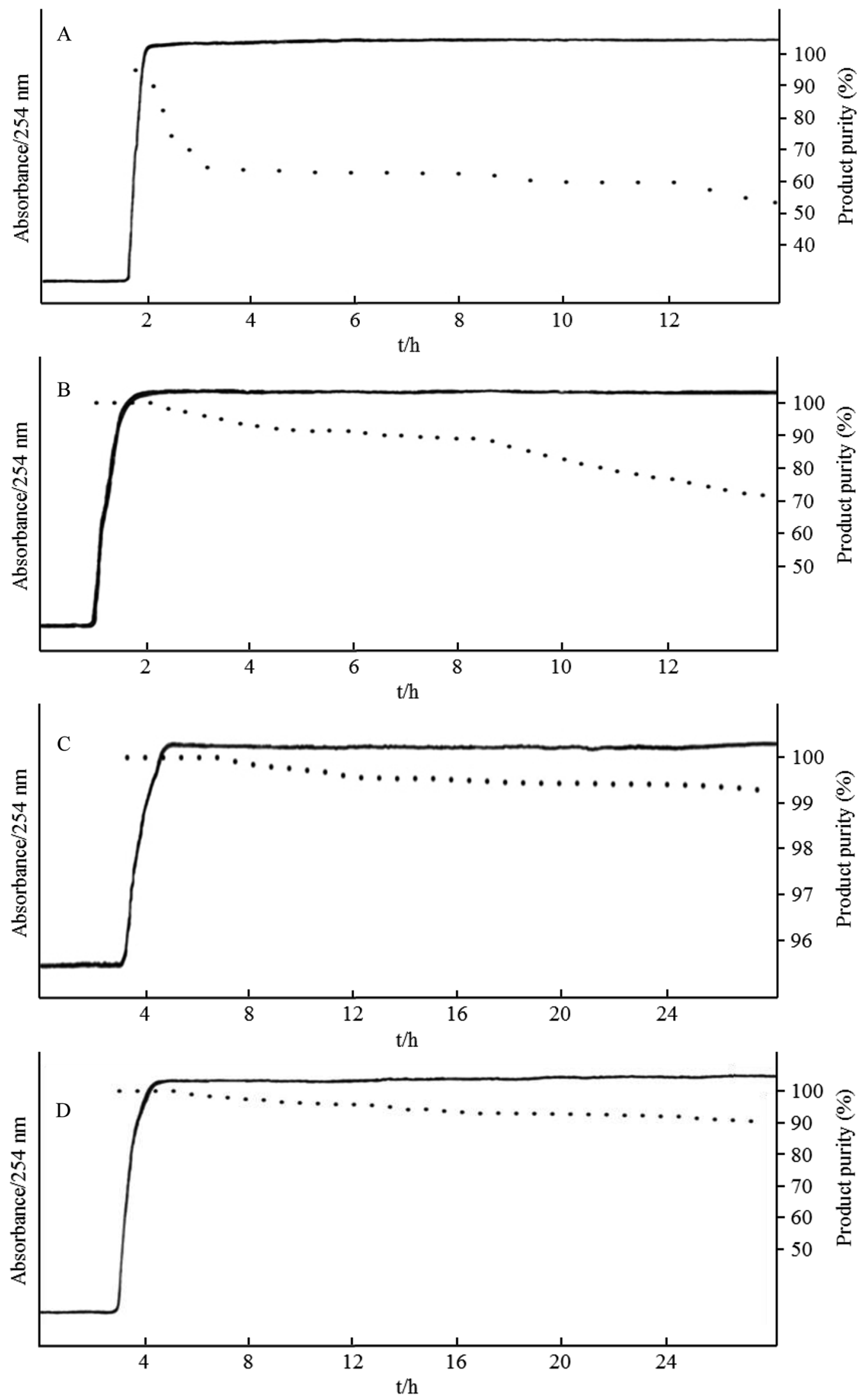

Fig. 5 Effect of the HSCCC bioreactor at different flow rates. (A) $3.0 \mathrm{~mL} \mathrm{~min}^{-1}$, (B) $2.5 \mathrm{~mL} \mathrm{~min}^{-1}$, (C) $2.0 \mathrm{~mL} \mathrm{~min}^{-1}$, and (D) $1.0 \mathrm{~mL} \mathrm{~min}^{-1}$. Solvent system: ethyl acetate/buffer solution (1:1, v/v). Enzyme: $750 \mathrm{mg} \mathrm{L}^{-1}$ of $\beta$-glucosidase. Substrate: $62.5 \mathrm{mg} \mathrm{L}^{-1}$ of genistin. Separation mode: FWD-OUT. Rotation speed: $800 \mathrm{rpm}$. Detection wavelength: $254 \mathrm{~nm}$. Biotransformation temperature: $40{ }^{\circ} \mathrm{C}$. 


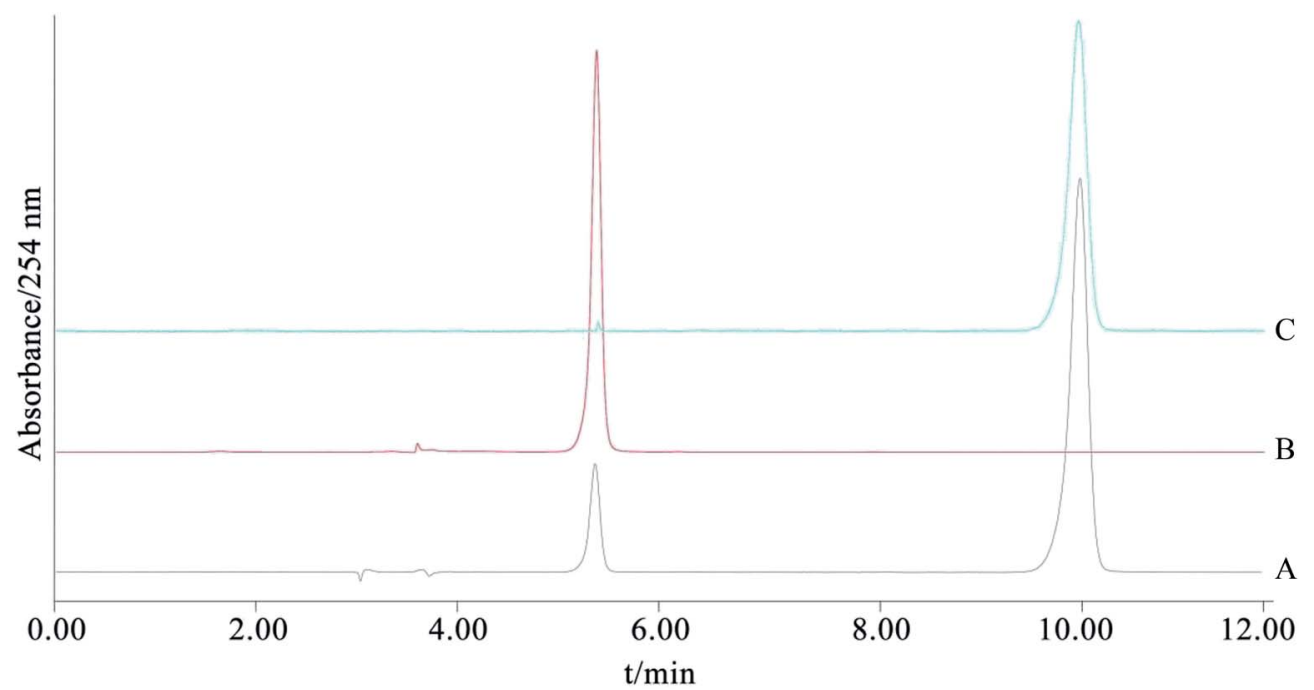

Fig. 6 HPLC chromatograms of the genistin and genistein. (A) Mixture of genistin and genistein, (B) genistin, and (C) genistein. Experimental conditions: Waters Symmetry $\mathrm{C}_{18}$ column $\left(5 \mu \mathrm{m}, 4.6 \mathrm{~mm} \times 250 \mathrm{~mm}\right.$, i.d.), mobile phase: methanol/water $(70: 30, \mathrm{v} / \mathrm{v})$, flow-rate: $1.0 \mathrm{~mL} \mathrm{~min}{ }^{-1}$, detection wavelength: $254 \mathrm{~nm}$, and injection volume: $10 \mu \mathrm{L}$.

stationary phase, accumulates to high concentration, and results in the by-product inhibition of $\beta$-glucosidase.

\subsection{Identification of the product}

ESI-MS $m / z: 271.2415[\mathrm{M}+\mathrm{H}]^{+} .{ }^{1} \mathrm{H}-\mathrm{NMR}\left(\mathrm{DMSO}-d_{6}, 400 \mathrm{MHz}\right) \delta$ : 12.93 (1H, s, OH-5), 10.83 (1H, s, OH-7), 9.55 (1H, s, OH-4'), 8.29 $(1 \mathrm{H}, \mathrm{s}, \mathrm{H}-2), 7.35\left(2 \mathrm{H}, \mathrm{d}, J=8.5 \mathrm{~Hz}, \mathrm{H}-2^{\prime}, 6^{\prime}\right), 6.80(2 \mathrm{H}, \mathrm{d}, J=$ $\left.8.5 \mathrm{~Hz}, \mathrm{H}-3^{\prime}, 5^{\prime}\right), 6.36(1 \mathrm{H}, \mathrm{d}, J=2.0 \mathrm{~Hz}, \mathrm{H}-8), 6.20(1 \mathrm{H}, \mathrm{d}, J=$ $2.0 \mathrm{~Hz}, \mathrm{H}-6)$. After comparing the data with the reported values, ${ }^{20}$ the chemical structure was identified as genistein.

\section{Conclusions}

In the present study, a novel HSCCC bioreactor was established for the efficient biotransformation of genistein from genistin. A suitable solvent system for the HSCCC bioreactor was chosen according to the enzyme activity (i.e. $K_{\mathrm{D}}$ values for the substrate and product). The HSCCC bioreactor parameters were selected as FWD-OUT and $800 \mathrm{rpm}$ with a retention of the stationary phase as the index. Using the optimal bioreactor parameters, different flow rates for the substrate solution were investigated, and $2.0 \mathrm{~mL} \min ^{-1}$ was chosen as the optimal flow rate with a conversion rate of over $90 \%$ within $24 \mathrm{~h}$. The established bioreactor was a novel type of immobilized enzyme reactor with the advantages of simple operation as well as the ability to immobilize and recycle the enzyme; moreover, the established bioreactor can be applied in the preparation of genistein and other biotransformations of natural products.

\section{Conflicts of interest}

All authors declare no conflicts of interest.

\section{Acknowledgements}

The authors gratefully acknowledge the financial support provided by the National Natural Science Foundation of China (21506119), Shandong Province Major Scientific and Technological Innovation Project (2017CXGC1301, 2017CXGC1308), Primary Research \& Development Plan of Shandong Province (2017GSF216002), and Natural Science Foundation of Shandong Province (ZR2017BC061).

\section{References}

1 C. M. Bargues, M. Ingles, L. G. Mallench, J. S. Ros, V. B. Costa, V. H. Perez, P. G. Tarraga, M. Dromant, C. Borras and J. M. G. Verdugo, Clearing Amyloid$\beta$ through PPAR $\gamma /$ ApoE Activation by Genistein is a Treatment of Experimental Alzheimer's Disease, Free Radic. Biol. Med., 2017, 108, S44.

2 M. Imaisumida, S. Majid, P. Dasgupta, P. Kulkarni, S. Saini, D. Bhagirath, T. Kato, S. Maekawa, Y. Hashimoto and M. Shiina, Abstract 3449: genistein inhibits renal cancer progression through long non-coding RNA HOTAIR suppression, Cancer Res., 2017, 77, 3449.

3 S. Jaskulski, A. Y. Jung, A. Rudolph, T. Johnson, K. Thöne, E. Herpel, P. Sinn and J. Chang-Claude, Genistein and enterolactone in relation to Ki-67 expression and HER2 status in postmenopausal breast cancer patients, Mol. Nutr. Food Res., 2017, 61(11), 1700449.

4 W. F. Li, K. Yang, P. Zhu, H. Q. Zhao, Y. H. Song, K. C. Liu and W. F. Huang, Genistein Ameliorates Ischemia/ Reperfusion-Induced Renal Injury in a SIRT1-Dependent Manner, Nutrients, 2017, 9(4), 403-423.

5 T. R. Moore, R. B. Franks and C. Fox, Review of Efficacy of Complementary and Alternative Medicine Treatments for 
Menopausal Symptoms, J. Midwifery Women's Health, 2017, 62(7), 286-297.

6 M. I. Sumida, Y. Tanaka, R. Dahiya and S. Yamamura, Abstract 4430: genistein regulates non-coding RNA HOTAIR and epithelial-to-mesenchyme transition in renal cancer cells, Cancer Res., 2018, 78, 4430.

7 X. Zhang, K. L. Cook, A. Warri, I. M. Cruz, M. Rosim, J. Riskin, W. Helferich, D. Doerge, R. Clarke and L. Hilakivi-Clarke, Lifetime genistein intake increases the response of mammary tumors to tamoxifen in rats, Clin. Cancer Res., 2017, 23(3), 814-824.

8 T. Izumi, M. K. Piskula, S. Osawa, A. Obata, K. Tobe, M. Saito, S. Kataoka, Y. Kubota and M. Kikuchi, Soy isoflavone aglycones are absorbed faster and in higher amounts than their glucosides in humans, J. Nutr., 2000, 130(7), 1695-1699.

9 M. K. Piskula, J. Yamakoshi and Y. Iwai, Daidzein and genistein but not their glucosides are absorbed from the rat stomach, FEBS Lett., 1999, 447(2-3), 287-291.

10 C. H. Lee, L. Yang, J. Z. Xu, S. Y. V. Yeung, Y. Huang and Z. Y. Chen, Relative antioxidant activity of soybean isoflavones and their glycosides, Food Chem., 2005, 90(4), 735-741.

11 W. D. Chiang, C. J. Shih and Y. H. Chu, Optimization of acid hydrolysis conditions for total isoflavones analysis in soybean hypocotyl by using RSM, Food Chem., 2001, 72(4), 499-503.

12 S. J. Yeom, B. N. Kim, Y. S. Kim and D. K. Oh, Hydrolysis of isoflavone glycosides by a thermostable $\beta$-glucosidase from Pyrococcus furiosus, J. Agric. Food Chem., 2012, 60(6), 15351541.

13 D. Y. Zhang, Y. G. Zu, Y. J. Fu, M. Luo, W. Wang, C. B. Gu and X. H. Yao, Application of immobilized enzymes to accelerate the conversion of; genistin to genistein in pigeon pea root extracts and the evaluation; their antioxidant activity, Ind. Crops Prod., 2013, 42(3), 409-415.
14 S. T. Morthensen, A. S. Meyer, H. Jørgensen and M. Pinelo, Significance of membrane bioreactor design on the biocatalytic performance of glucose oxidase and catalase: free vs. immobilized enzyme systems, Biochem. Eng. J., 2017, 17, 41-47.

15 J. Xu, C. Liu, M. Wang, L. Shao, L. Deng, K. Nie and F. Wang, Rotating packed bed reactor for enzymatic synthesis of biodiesel, Bioresour. Technol., 2017, 224, 292-297.

16 T. Chen, H. Li, D. Zou, Y. Liu, C. Chen, G. Zhou and Y. Li, Separation of three anthraquinone glycosides including two isomers by preparative high-performance liquid chromatography and High-speed counter-current chromatography from Rheum tanguticum Maxim, J. Sep. Sci., 2016, 39(16), 3105-3112.

17 T. Chen, P. Wang, N. Wang, C. Sun, X. Yang, H. Li, G. Zhou and Y. Li, Separation of three polar compounds from Rheum tanguticum by high-speed countercurrent chromatography with an ethyl acetate/glacial acetic acid/water system, $J$. Sep. Sci., 2017, 225, 55-61.

18 Q. Gao, R. Ma, L. Chen, S. Shi, P. Cai, S. Zhang and H. Xiang, Antioxidant profiling of vine tea (Ampelopsis grossedentata): off-line coupling heart-cutting HSCCC with HPLC-DADQTOF-MS/MS, Food Chem., 2017, 225, 55-61.

19 H. Zhao, X. Hu, X. Chen, S. Shi, X. Jiang, X. Liang, W. Chen and S. Zhang, Analysis and improved characterization of minor antioxidants from leaves of Malus doumeri using a combination of major constituents' knockout with highperformance liquid chromatography-diode array detectorquadrupole time-of-flight tandem mass spectrometry, $J$. Chromatogr. A, 2015, 1398, 57-65.

20 C. Lang'at Thoruwa, T. T. Song, J. Hu, A. L. Simons and P. A. Murphy, A Simple Synthesis of 7,4'-Dihydroxy-6methoxyisoflavone, Glycitein, the Third Soybean Isoflavone, J. Nat. Prod., 2003, 66(1), 149-151. 